Article

\title{
An Easy-To-Use Survival Score Compared to Existing Tools for Older Patients with Cerebral Metastases from Colorectal Cancer
}

\author{
Dirk Rades ${ }^{1, *}$, Trang Nguyen ${ }^{1}$, Stefan Janssen ${ }^{1,2}$ and Steven E. Schild ${ }^{3}$ \\ 1 Department of Radiation Oncology, University of Luebeck, 23570 Luebeck, Germany; \\ trangnguyen.dv@googlemail.com (T.N.); st-janssen@gmx.net (S.J.) \\ 2 Medical Practice for Radiotherapy and Radiation Oncology, 30159 Hannover, Germany \\ 3 Department of Radiation Oncology, Mayo Clinic, Scottsdale, AZ 85250, USA; sschild@mayo.edu \\ * Correspondence: dirk.rades@uksh.de; Tel.: +49-451-5004-5400
}

Received: 12 March 2020; Accepted: 28 March 2020; Published: 30 March 2020

\begin{abstract}
An easy-to-use survival score was developed specifically for older patients with cerebral metastases from colorectal cancer, and was compared to existing tools regarding the accuracy of identifying patients who die in $\leq 6$ months and those who survive for $\geq 6$ months. The new score was built from 57 patients receiving whole-brain irradiation. It included three groups identified from 6-month survival rates based on two independent predictors (performance status and absence/presence of non-cerebral metastases), with 6-month survival rates of $0 \%$ (0 points), $26 \%$ ( 1 point), and $75 \%$ ( 2 points), respectively. This score was compared to diagnosis-specific scores, namely the diagnosis-specific graded prognostic assessment (DS-GPA), the Dziggel-Score and the WBRT-30-CRC (whole-brain radiotherapy with 30 Gy in 10 fractions for cerebral metastases from colorectal cancer) score and to a non-diagnosis-specific score for older persons (Evers-Score). Positive predictive values were 100\% (new score), 87\% (DS-GPA), 86\% (Dziggel-Score), 91\% (WBRT-30-CRC), and 100\% (Evers-Score), respectively, for patients dying $\leq 6$ months, and $75 \%$, $33 \%, 75 \%, 60 \%$, and $45 \%$, respectively, for survivors $\geq 6$ months. Of the five tools, the new score and the Evers-Score were most precise in identifying patients dying $\leq 6$ months. The new score and the Dziggel-Scores were best at identifying patients surviving $\geq 6$ months. When combining the results, the new score appeared preferable to the existing tools. The score appears not necessary for patients with additional liver metastases, since their 6-month survival rate was $0 \%$.
\end{abstract}

Keywords: colorectal cancer; older persons; cerebral metastases; radiation therapy; survival scores

\section{Introduction}

Colorectal cancer ranks as the third most common malignant disease worldwide, with an expected increase of the number of deaths until 2035 [1-3]. When compared to other cancer types, cerebral metastases occur less frequently, in only 1-2\% of patients having colorectal cancers [4-6]. Many of these patients are treated with radiation therapy that, depending on the number and size of cerebral lesions, is administered locally as single-fraction radiosurgery and fractionated stereotactic radiation therapy, or as treatment of the entire brain (whole-brain irradiation) [7]. Both local irradiation and whole-brain irradiation can also be combined when appropriate. Local radiation therapy is generally limited to $\leq 5$ cerebral lesions with diameters of $\leq 3-4 \mathrm{~cm}$. Many other patients receive whole-brain irradiation. For this type of radiation, different dose fractionations exist, including one-week treatment with $20 \mathrm{~Gy}$ in five fractions, two-week treatment with 30 Gy in 10 fractions, or treatment with doses beyond 30 Gy lasting up to four weeks [7]. Each of these programs is not optimal for each patient. For example, patients with shorter expected survival times should be considered for $20 \mathrm{~Gy}$ in five fractions, to avoid spending too 
much of their limited lifespan in treatment. In patients expected to have longer survival times, outcomes can be improved with doses > 30 Gy [8]. Moreover, the modern approaches of hippocampus-sparing and addition of memantine can significantly reduce neurocognitive decline, an important late toxicity of whole-brain-irradiation [9-11]. The risk of experiencing this late toxicity increases with time, and therefore, gains importance in longer-term survivors. Thus, physicians are interested in accurate knowledge of a patient's prognosis, which can be improved with survival scores. It would be ideal to have separate scores for specific cancer types to account for differences in tumor biology and prognoses. A few tools already exist for patients with cerebral metastases from colon or rectal cancers [12-15]. However, none of these scores has been created specifically for the expanding group of older patients. This study provided the first score, particularly for older patients with cerebral metastases from colorectal cancers. Moreover, the new score was compared to existing instruments, one non-diagnosis-specific and three diagnosis-specific tools, with respect to accurately identifying patients who die within 6 months and patients who survive for 6 months or longer. The diagnosis-specific scores were the diagnosis-specific graded prognostic assessment (DS-GPA) classification for gastro-intestinal cancers, the Dziggel-Score for less radiosensitive tumors, and the WBRT-30-CRC (whole-brain radiotherapy with $30 \mathrm{~Gy}$ in 10 fractions for cerebral metastases from colorectal cancer) score [12-15]. These tools were not specifically created for older patients. Moreover, the DS-GPA and the Dziggel-Score also include primary tumor types different from colorectal cancer. The Evers-Score was created from a cohort of elderly patients, but includes many different tumor entities [16].

\section{Results}

\subsection{Creation of the New Score}

The median survival time in the entire series was 2 months, and the 3- and 6-month survival rates were $33 \%$ and $18 \%$, respectively. Fifty-three patients died during the period of follow-up. The cause for death was known in 33 patients. In these patients, death was always related to intra- or extra-cerebral progression of colorectal cancer. A Karnofsky performance score (KPS) of $\geq 70 \%(p=0.0002)$ and absence of non-cerebral metastases ( $p=0.021$ ) were associated with increased survival on univariate analyses (Table 1). In the additional multivariate analysis, both the KPS (hazard ratio: 2.97; 95\% confidence interval: $1.61-5.65 ; p=0.0005$ ) and non-cerebral metastases (hazard ratio: 3.03 ; 95\% confidence interval: $1.29-8.91 ; p=0.009$ ) proved to be independent predictors. Therefore, both factors were incorporated in the new scoring tool. The scoring points assigned to these factors are presented in Table 2 . The scores obtained for individual patients were $0(n=26), 1(n=27)$, or $2(n=4)$ points. The corresponding survival rates were $8 \%, 52 \%$, and $75 \%$, respectively, after 3 months, and $0 \%, 26 \%$, and $75 \%$, respectively, after 6 months (Figure 1, $p<0.0001$ ). Thus, the positive predictive value (PPV) to correctly identify patients dying within 6 months was 100\% (0-points group), and the PPV to identify patients living for at least 6 months was $75 \%$ (2-points group).

Of the 20 patients who had liver metastases, no patient survived longer than 5 months. Thus, the probability of dying within 6 months was 100\%. In patients without liver metastases, 6-month survival rates were $0 \%$ (0 of 13 patients) in the 0 -points group, 35\% (7 of 20 patients) in the 1-point group, and 75\% (3 of 4 patients) in the 2-points group, respectively. The PPVs were 100\% and 75\%, respectively, to correctly predict death within 6 months and survival for at least 6 months. 
Table 1. Results of the univariate analysis of survival.

\begin{tabular}{|c|c|c|c|}
\hline \multirow{2}{*}{ Potential Prognostic Factor } & \multicolumn{2}{|c|}{ Survival at } & \multirow{2}{*}{$p$-Value } \\
\hline & 3 Months (\%) & 6 Months (\%) & \\
\hline $\begin{array}{l}\text { Radiation therapy schedule } \\
20 \text { Gy in } 5 \text { fractions } \\
30 \text { Gy in } 10 \text { fractions } \\
36-40 \text { Gy in } 12-20 \text { fractions }\end{array}$ & $\begin{array}{l}45 \\
29 \\
33\end{array}$ & $\begin{array}{l}18 \\
13 \\
27\end{array}$ & 0.553 \\
\hline $\begin{array}{l}\text { Age at irradiation of cerebral } \\
\text { metastases } \\
65-73 \text { years } \\
>73 \text { years } \\
\text { Gender } \\
\text { Female } \\
\text { Male }\end{array}$ & $\begin{array}{l}37 \\
30\end{array}$ & $\begin{array}{l}20 \\
15\end{array}$ & 0.978 \\
\hline $\begin{array}{c}\text { Karnofsky Performance Score } \\
\leq 60 \% \\
\geq 70 \%\end{array}$ & $\begin{array}{l}17 \\
52\end{array}$ & $\begin{array}{c}0 \\
37\end{array}$ & 0.0002 \\
\hline $\begin{array}{l}\text { Cancer site } \\
\text { Colon } \\
\text { Rectum }\end{array}$ & $\begin{array}{l}28 \\
43\end{array}$ & $\begin{array}{l}14 \\
24\end{array}$ & 0.303 \\
\hline $\begin{array}{l}\text { Number of cerebral metastases } \\
\text { One to three lesions } \\
\text { At least four lesions }\end{array}$ & $\begin{array}{l}36 \\
31\end{array}$ & $\begin{array}{l}24 \\
13\end{array}$ & 0.476 \\
\hline $\begin{array}{l}\text { Non-cerebral metastases } \\
\text { Absence } \\
\text { Presence }\end{array}$ & $\begin{array}{l}75 \\
27\end{array}$ & $\begin{array}{l}38 \\
14\end{array}$ & 0.021 \\
\hline $\begin{array}{l}\text { Time period from diagnosis } \\
\text { of colorectal cancer until RT } \\
\text { of cerebral metastases } \\
\quad \leq 30 \text { months } \\
\quad>30 \text { months }\end{array}$ & $\begin{array}{l}24 \\
43\end{array}$ & $\begin{array}{l}10 \\
25\end{array}$ & 0.605 \\
\hline $\begin{array}{c}\text { Chemotherapy before irradiation } \\
\text { of cerebral metastases } \\
\text { Not administered } \\
\text { Administered }\end{array}$ & $\begin{array}{l}10 \\
38\end{array}$ & $\begin{array}{c}0 \\
21\end{array}$ & 0.076 \\
\hline $\begin{array}{c}\text { Controlled primary tumor } \\
\text { Not controlled } \\
\text { Controlled }\end{array}$ & $\begin{array}{l}30 \\
36\end{array}$ & $\begin{array}{l}20 \\
17\end{array}$ & 0.260 \\
\hline
\end{tabular}

Table 2. Scoring points assigned to the independent prognostic factors.

\begin{tabular}{cccc}
\hline \multirow{2}{*}{ Prognostic Factor } & \multicolumn{2}{c}{ Survival at } & \multirow{2}{*}{ Scoring Points } \\
\cline { 2 - 3 } & 3 Months (\%) & $\mathbf{6}$ Months (\%) & \\
\hline $\begin{array}{c}\text { Karnofsky Performance } \\
\text { Score }\end{array}$ & 17 & 0 & 0 \\
$\leq 60 \%$ & 52 & 37 & 1 \\
$\geq 70 \%$ & & & 1 \\
\hline $\begin{array}{c}\text { Non-cerebral metastases } \\
\text { Absence }\end{array}$ & 75 & 38 & 0 \\
Presence & 27 & 14 & \\
\hline
\end{tabular}




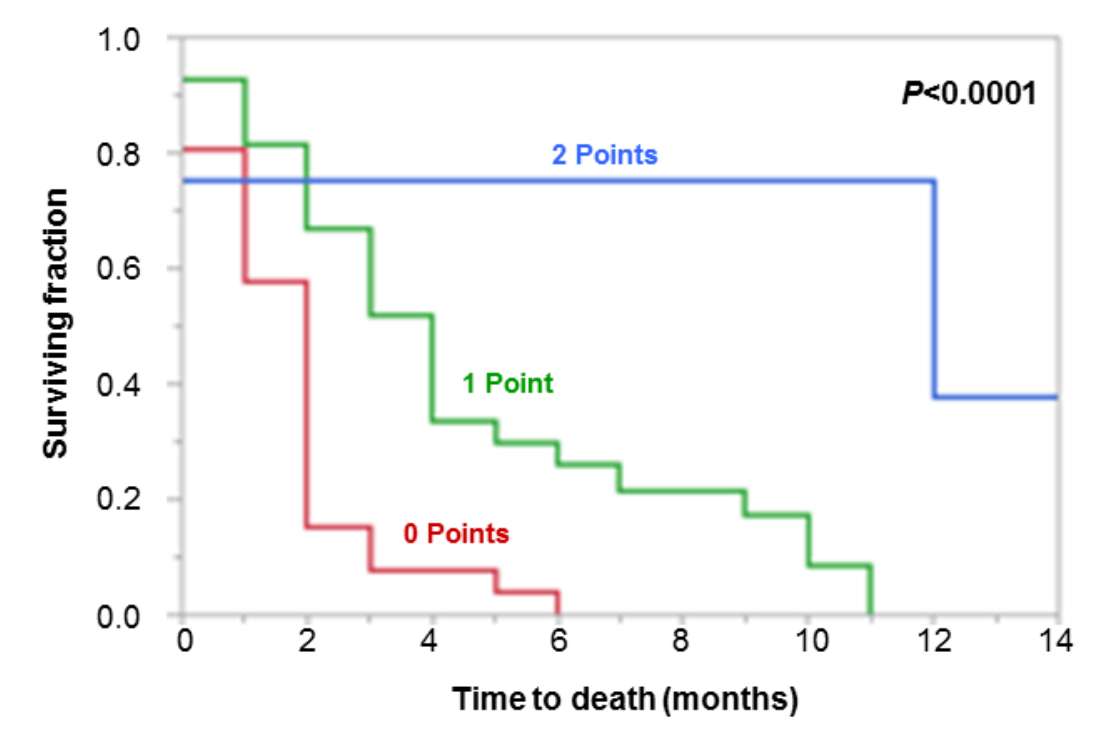

Figure 1. Kaplan-Meier curves of the three groups for the new score.

\subsection{Comparison of the New Score to Existing Tools}

The 6-month survival probabilities of the prognostic groups of the new score, DS-GPA classification [12,13], Dziggel-Score [14], WBRT-30-CRC [15], and Evers-Score [16] are summarized in Table 3. The positive predictive values (PPVs) for the poor-prognosis groups to accurately identify patients who died within 6 months were 100\% (new score), 100\% (Evers-Score), 91\% (WBRT-30-CRC), 87\% (DS-GPA classification) and 86\% (Dziggel-Score), respectively. In addition, the PPVs of the favorable-prognosis groups to accurately identify patients living for at least 6 months were 75\% (new score), 75\% (Dziggel-Score), 60\% (WBRT-30-CRC), 45\% (Evers-Score), and 33\% (DS-GPA), respectively. For the DS-GPA, a range of 3.0-4.0 points was selected as the favorable-prognosis group, since only one patient had a score of $>3.0$. [12,13].

Table 3. Prognosis groups of the compared tools with scoring points and 6-month survival rates [12-16].

\begin{tabular}{|c|c|c|c|c|c|c|c|c|c|c|}
\hline \multirow[t]{2}{*}{ Prognosis } & \multicolumn{2}{|c|}{ New Score } & \multicolumn{2}{|c|}{ WBRT-30-CRC } & \multicolumn{2}{|c|}{ DS-GPA Scores } & \multicolumn{2}{|c|}{ Dziggel-Score } & \multicolumn{2}{|c|}{ Evers-Score } \\
\hline & $\begin{array}{l}\text { Scoring } \\
\text { Points }\end{array}$ & $\begin{array}{l}\text { 6-Month } \\
\text { Survival }\end{array}$ & $\begin{array}{l}\text { Scoring } \\
\text { Points }\end{array}$ & $\begin{array}{l}\text { 6-Month } \\
\text { Survival }\end{array}$ & $\begin{array}{l}\text { Scoring } \\
\text { Points }\end{array}$ & $\begin{array}{l}\text { 6-Month } \\
\text { Survival }\end{array}$ & $\begin{array}{l}\text { Scoring } \\
\text { Points }\end{array}$ & $\begin{array}{l}\text { 6-Month } \\
\text { Survival }\end{array}$ & $\begin{array}{l}\text { Scoring } \\
\text { Points }\end{array}$ & $\begin{array}{l}\text { 6-Month } \\
\text { Survival }\end{array}$ \\
\hline Poor & 0 & $\begin{array}{c}0 \% \\
(0 / 26)\end{array}$ & $3-4$ & $\begin{array}{c}9 \% \\
(2 / 23)\end{array}$ & $0.0-1.0$ & $\begin{array}{c}13 \% \\
(6 / 46)\end{array}$ & $5-8$ & $\begin{array}{c}14 \% \\
(7 / 49)\end{array}$ & $3-6$ & $\begin{array}{c}0 \% \\
(0 / 28)\end{array}$ \\
\hline Intermediate & 1 & $\begin{array}{c}26 \% \\
(7 / 27)\end{array}$ & $5-9$ & $\begin{array}{c}17 \% \\
(5 / 29)\end{array}$ & $1.5-$ & $\begin{array}{l}38 \% \\
(3 / 8)\end{array}$ & $9-1$ & $\begin{array}{c}0 \% \\
(0 / 4)\end{array}$ & $7-9$ & $\begin{array}{c}28 \% \\
(5 / 18)\end{array}$ \\
\hline Favorable & 2 & $\begin{array}{l}75 \% \\
(3 / 4)\end{array}$ & 10 & $\begin{array}{l}60 \% \\
(3 / 5)\end{array}$ & $3.0-4.0$ & $\begin{array}{l}33 \% \\
(1 / 3)\end{array}$ & $12-14$ & $\begin{array}{l}75 \% \\
(3 / 4)\end{array}$ & $10-12$ & $\begin{array}{c}45 \% \\
(5 / 11)\end{array}$ \\
\hline
\end{tabular}

For the new score, the difference between the 0 points (poor prognosis) and the 1-point group (intermediate prognosis) was significant ( $p=0.010$, two-tailed Fisher's exact test); a trend $(p=0.087)$ was found for the difference between the 1-point and the 2-points group (favorable prognosis). The differences between the poor-prognosis and the intermediate-prognosis group was significant for the Evers-Score $(p=0.006)$ but not for DS-GPA $(p=0.118)$, WBRT-30-CRC $(p=0.444)$, or Dziggel-Score $(p=1.000)$ groups [12-16]. A trend regarding the difference between the intermediate-prognosis and the favorable-prognosis group was found for the WBRT-30-CRC ( $\mathrm{p}=0.072)$. Differences were not significant for the Evers-Score $(p=0.432)$, DS-GPA $(p=1.000)$, and Dziggel-Score $(p=0.143)$ [12-16].

The new score was the only one that achieved highest PPVs (i.e., highest levels of accuracy) for both identification of patients who died within 6 months and patients who survived for at least 6 months. Moreover, the new score was the only tool that, at the same time, showed a significant 
difference between the poor-prognosis and the intermediate-prognosis group, and at least a trend regarding the difference between the intermediate-prognosis and the favorable-prognosis group.

\section{Discussion}

Older patients have come more into the focus of physicians involved in cancer treatment. These patients often present with significant underlying diseases, such as diabetes, coronary heart disease, dementia, and many others. Moreover, the function of critical organs, such as the liver and kidneys, can be markedly reduced. Therefore, many of these patients cannot receive aggressive treatments like younger patients. Since the comorbidity index and organ function vary widely between individual older cancer patients, they require personalized treatment protocols to achieve the best outcome. This is particularly true for palliative situations, including metastatic spread to the brain. When physicians aim to tailor the treatment to a patient, they need to be aware of the patient's residual lifespan. This particular knowledge can be provided by survival scores that ideally should be created for each type of cancer spreading to the brain. In the present study, we have developed the first score particularly designed for older patients with cerebral metastases from colorectal cancer.

Two independent predictors of survival, i.e., performance status and non-cerebral metastases, formed the basis of this score, which included three prognostic groups. Patients of the 0-points group had a median survival of only 2 months, and a 3-month survival rate of only $8 \%$. No patient reached the 6-month survival time point. Regarding this extraordinarily poor prognosis, these patients, if irradiated, should receive 20 Gy in five fractions, since this regimen lasts only five working days. According to a previous study of 442 patients treated with whole-brain irradiation alone for multiple cerebral metastases, this regimen achieved similar cerebral control and survival as the two-week $30 \mathrm{~Gy}$ regimen in 10 fractions [17]. Moreover, one may also consider omitting radiation therapy and use best supportive care alone for patients of the 0-points group. In a randomized trial of 538 lung cancer patients with cerebral metastases and poor survival, the addition of whole-brain irradiation (20 Gy in five fractions) for the best supportive care did not provide a significant benefit in terms of survival and quality of life [18]. The quality-adjusted life years were 46.4 days with and 41.7 days without radiation therapy.

In the 1-point group, patients had an intermediate survival prognosis with a median survival of 4 months, and 3- and 6-month rates of $52 \%$ and $26 \%$, respectively. No patient survived longer than 11 months. These patients may be considered for $30 \mathrm{~Gy}$ in 10 fractions, globally the most common regimen of whole-brain irradiation [7]. Patients of the 2-points group had much more favorable prognoses, with a median survival time of 12 months and $75 \%$ of the patients surviving for 6 months or longer. Unfortunately, this group was quite small, and accounted for only $7 \%$ of the patients in this study. These patients should be considered for whole-brain irradiation with doses $>30 \mathrm{~Gy}$. In a previous study of 186 longer-term survivors, 40 Gy in 20 fractions, when compared to 30 Gy in 10 fractions, resulted in significantly increased 1-year cerebral control ( $44 \%$ vs. $28 \%$, respectively), and survival (61\% vs. $50 \%$, respectively) [8]. A small study of 23 patients with cerebral metastases from malignant melanoma suggested that 36Gy in 12 fractions was not inferior to $40 \mathrm{~Gy}$ in 20 fractions regarding 6-month cerebral control ( $42 \%$ vs. $17 \%$, respectively; $p=0.28$ ) and survival ( $50 \%$ vs. $36 \%$, respectively; $p=0.75$ ) [19]. Moreover, patients of the 2-points group may be candidates for the comparably new approaches of hippocampus-sparing and the addition of memantine. Reducing the radiation dose to the hippocampi led to a reduction of cognitive decline in a phase II study of patients receiving $30 \mathrm{~Gy}$ in 10 fractions [9]. At 4 months after irradiation, cognitive decline was found in $7 \%$ of the 42 patients receiving hippocampus-sparing, compared to $30 \%$ in a historical control $(p<0.001)$ [9]. In a randomized trial that included 554 patients, the addition of memantine to whole-brain irradiation (37.5Gy in 15 fractions), the interval to cognitive decline was significantly longer in patients receiving the memantine (hazard ratio $0.78, p=0.01$ ) [10]. Moreover, at least at one time point with significantly better results regarding executive function, processing speed, and delayed recognition was found in the memantine group. In a recently published phase III trial of 518 patients receiving whole-brain 
irradiation, hippocampus-sparing and memantine were combined and compared to memantine without sparing of the hippocampi [11]. The combined approach resulted in better preservation of cognitive function without impairing cerebral progression-free survival and overall survival.

In a second step, the new score was compared to four existing tools with respect to the PPVs to correctly identify patients dying within 6 months and patients surviving for at least 6 months [12-16]. For identification of patients dying within 6 months, the new score achieved the best possible accuracy, i.e., a PPV of $100 \%$. This high PPV was also achieved by the Evers-Score, which was also developed specifically for older patients [16]. These results support the idea of considering older patients a separate group and developing separate prognostic tools for them. The other three tools, which were diagnosis-specific but not designed for older patients, achieved accuracies (PPVs) of $86 \%$ (Dziggel-Score [14]), 87\% (DS-GPA [12,13]), and 91\% (WBRT-30-CRC [15]), which can also be considered quite high. When aiming to identify patients living for at least 6 months, all five tools were less accurate. The highest accuracy (PPV of 75\%) was found for the new score and the Dziggel-Score [14], whereas the PPVs of the other three tools were even lower with 33\% (DS-GPA [12,13]), 45\% (Evers-Score [16]), and $60 \%$ (WBRT-30-CRC [15]), respectively. Thus, when combining both estimations, the new score appeared preferable, since it achieved the highest PPVs for both identification of patients dying within 6 months and patients surviving for at least 6 months.

However, when using the new score or any of the existing tools, one has to be aware that they were all created in retrospective studies that might have introduced hidden selection biases. Another limitation of the present study was its comparably small sample size. Validation of the new score in a larger cohort of patients is warranted. Moreover, application of the new score appears not necessary for patients with liver metastases in addition to cerebral metastases. In the present study, the 6-month survival rate of these patients was $0 \%$. Thus, the PPV of accurate identification of patients dying within 6 months was $100 \%$. In patients without liver metastases, the 6-month survival rates and the PPVs of the 0-points and 2-points group were the same as in the entire cohort. Therefore, the new score will be of value for physicians who wish to tailor a treatment regimen to an elderly patient with cerebral metastases from colorectal cancer without additional liver metastases.

\section{Materials and Methods}

In a series of 57 older patients (aged at least 65 years [20,21]), who were treated with whole-brain irradiation for cerebral metastases from colorectal cancer between 1999 and 2019, the dose-fractionation schedule plus seven pre-radiotherapy factors were retrospectively analyzed for 3- and 6-month survival. These factors were obtained from an anonymized database and included the dose-fractionation schedule of radiation therapy (20 Gy in 5 fractions vs. 30 Gy in 10 fractions vs. $36-40$ Gy in $12-20$ fractions), age at irradiation of the cerebral metastases (65-73 vs. $>73$ years; median age was 73 years), gender, Karnofsky performance score ( $\leq 60 \%$ vs. $\geq 70 \%$; median score was $60 \%$ ), cancer site (colon vs. rectum), number of cerebral metastases ( 1 to 3 vs. at least 4 lesions; median number was 4 lesions), non-cerebral metastases (absence vs. presence), time period from diagnosis of colorectal cancer until RT of cerebral metastases ( $\leq 30$ vs. $>30$ months; median time period was 30 months), chemotherapy before irradiation of cerebral metastases (not administered vs. administered), and control of the primary tumor (not controlled vs. controlled). The distributions of these factors are shown in Table 4. Co-morbidity was not included as an additional factor, since co-morbidity indices are usually dominated by presence of metastatic (solid) tumors, which applies to the entire cohort of this study [22,23]. In addition, co-morbidity and the Karnofsky performance score have to be considered confounding variables. The study was approved by the responsible ethics committee at the University of Luebeck. For univariate analyses, we used the Kaplan-Meier method plus the log-rank test. Significant $(p<0.05)$ factors were additionally evaluated in a multivariate analysis (Cox proportional hazard model) to considerably reduce the potential influence of confounding factors. The prognostic factors that proved to be independent were incorporated in the new survival score. For each independent 
prognostic factor, 0 points and 1 point, respectively, were given for worse and better survival outcomes. Finally, the points of each factor were added for each patient's individual score.

Table 4. Summary of the potential prognostic factors.

\begin{tabular}{|c|c|}
\hline Potential Prognostic Factor & $n$ Patients (\%) \\
\hline \multicolumn{2}{|l|}{ Radiation therapy schedule } \\
\hline 20 Gy in 5 fractions & $11(19.3)$ \\
\hline 30 Gy in 10 fractions & $31(54.4)$ \\
\hline \multicolumn{2}{|l|}{$36-40$ Gy in $12-20$ fractions } \\
\hline \multicolumn{2}{|l|}{ Age at RT of cerebral metastases } \\
\hline $65-73$ years & $\begin{array}{l}30(52.6) \\
27(47.4)\end{array}$ \\
\hline \multicolumn{2}{|l|}{$>73$ years } \\
\hline Gender & \\
\hline Female & $\begin{array}{l}24(42.1) \\
33(579)\end{array}$ \\
\hline \multicolumn{2}{|l|}{ Male } \\
\hline \multicolumn{2}{|l|}{ Karnofsky Performance Score } \\
\hline$\leq 60 \%$ & $27(47.4)$ \\
\hline$\geq 70 \%$ & \\
\hline Cancer site & \\
\hline Colon & $36(63.2)$ \\
\hline \multicolumn{2}{|l|}{ Rectum } \\
\hline \multicolumn{2}{|l|}{ Number of cerebral metastases } \\
\hline 1 to 3 lesions & $25(43.9)$ \\
\hline \multicolumn{2}{|l|}{ At least 4 lesions } \\
\hline \multicolumn{2}{|l|}{ Non-cerebral metastases } \\
\hline Absence & $8(14.0)$ \\
\hline \multicolumn{2}{|l|}{ Presence } \\
\hline \multicolumn{2}{|l|}{ Time period from diagnosis of colorectal cancer until } \\
\hline RT of cerebral metastases & $29(50.9)$ \\
\hline$\leq 30$ months & $28(49.1)$ \\
\hline \multicolumn{2}{|l|}{$>30$ months } \\
\hline \multicolumn{2}{|l|}{ Chemotherapy before RT of cerebral metastases } \\
\hline Not administered & $10(17.5)$ \\
\hline \multicolumn{2}{|l|}{ Administered } \\
\hline \multicolumn{2}{|l|}{ Controlled primary tumor } \\
\hline Not controlled & $\begin{array}{l}10(1 \% .5) \\
47(825)\end{array}$ \\
\hline Controlled & $47(82.5)$ \\
\hline
\end{tabular}

The new score was compared to four existing tools: three diagnosis-specific scores, including colorectal cancer patients, and one non-diagnosis-specific tool designed for older patients. Comparisons were performed regarding the positive predictive values (PPVs) to accurately identify patients who will die within 6 months and patients who will survive for at least 6 months following radiation therapy [12-16]. The diagnosis-specific scores included the DS-GPA classification for gastro-intestinal cancers (Table 5); the Dziggel-Score for less radiosensitive tumors, including colorectal cancers, kidney cancer, and malignant melanoma (Table 6); and the WBRT-30-CRC for colorectal cancer (Table 7). The non-diagnosis-specific tool was the Evers-Score (Table 8). Survival time was calculated from the first day of radiation therapy. The PPVs were calculated by dividing the number of true positives through the number of all patients (true positives plus false positives). Discriminations between poor-prognosis and intermediate-prognosis groups and between intermediate-prognosis and favorable-prognosis groups were investigated for each tool with the two-tailed Fisher's exact test; $p<0.05$ were rated significant, and $p<0.10$ was considered to be showing a trend.

The PPVs to correctly predict death within 6 months and survival for at least 6 months were additionally calculated in patients who had liver metastases in addition to cerebral metastases, as well as in those patients without liver metastases. 
Table 5. Diagnosis-specific graded prognostic assessment (DS-GPA) for colorectal cancer patients with cerebral metastases $[12,13]$.

\begin{tabular}{cccccc}
\hline \multirow{2}{*}{ Prognostic Factor } & \multicolumn{5}{c}{ GPA Scoring Criteria } \\
\cline { 2 - 6 } & $\mathbf{0}$ & $\mathbf{1}$ & $\mathbf{2}$ & $\mathbf{3}$ & $\mathbf{4}$ \\
\hline $\begin{array}{c}\text { Karnofsky Performance } \\
\text { Score }\end{array}$ & $<70$ & 70 & 80 & 90 & 100 \\
\hline
\end{tabular}

Prognostic groups of the DS-GPA: 0.0-1.0, 1.5-2.5, 3.0, 3.5-4.0; higher scores = better prognoses [12,13].

Table 6. Scoring points of the Dziggel-Score for brain lesions from less radiosensitive tumors [14].

\begin{tabular}{cc}
\hline Prognostic Factor & Scoring Points \\
\hline Age & 4 \\
$<65$ years & 2 \\
$\geq 65$ years & \\
$<70$ & 4 \\
$\geq 70$ & \\
Karnofsky Performance Score & 6 \\
Non-cerebral metastases & 2 \\
Absence & \\
Presence & \\
\hline
\end{tabular}

Prognostic groups of the Dziggel-Score: 5-8, 9-11 and 12-14 points; higher scores = better prognoses [14].

Table 7. Scoring points of the WBRT-30-CRC (whole-brain radiotherapy with 30 Gy in 10 fractions for cerebral metastases from colorectal cancer) Score [15].

\begin{tabular}{cc}
\hline Prognostic Factor & Scoring Points \\
\hline Interval from first diagnosis of & \\
Colorectal cancer to WBRT & 3 \\
$\leq 26$ months & \\
$>26$ months & 1 \\
Karnofsky Performance Score & 5 \\
$\leq 70 \%$ & \\
$>70 \%$ & 2 \\
Number of brain metastases & 1 \\
$\geq 4$ &
\end{tabular}

Prognostic groups of the WBRT-30-CRC score: 3-4, 5-6, 7-9, and 10 points; higher scores $=$ better prognoses [15].

Table 8. Scoring points of the Evers-Score for elderly patients with cerebral metastases [16].

\begin{tabular}{cc}
\hline Prognostic Factor & Scoring Points \\
\hline Gender & 3 \\
Female & 2 \\
Male & \\
Karnofsky Performance Score & 0 \\
$<70 \%$ & 4 \\
$70 \%$ & 6 \\
$>70 \%$ & \\
Number of involved extracranial organs & 4 \\
0 & 3 \\
1 & 1 \\
$\geq 2$ &
\end{tabular}

Prognostic groups of the Evers-Score: 3-6, 7-9, 10-12, and 13 points; higher scores = better prognoses [16]. 


\section{Conclusions}

A new score is provided to help physicians predict the survival time of older patients with cerebral metastases form colorectal cancer and facilitate the design of a personalized treatment protocol, including dose-fractionation and technique of whole-brain irradiation. The new score was the only tool that achieved the highest accuracy among those compared for both identification of patients who died within 6 months and patients who survived for at least 6 months. Therefore, the new score can be considered preferable to the existing tools. Since the Evers-Score and the Dziggel-Score were as precise as the new score in identifying patients dying $\leq 6$ months and surviving $\geq 6$ months, respectively. Physicians should always consider validating the findings obtained with the new tool using these existing tools before they design an individual treatment regimen. The score appears not necessary for patients with additional liver metastases, since their 6-month survival rate was $0 \%$.

Author Contributions: Conceptualization, D.R., T.N., S.J., and S.E.S.; methodology, D.R., T.N., S.J., and S.E.S.; validation, D.R., T.N., S.J., and S.E.S.; formal analysis, D.R. and S.E.S.; investigation, D.R., T.N., S.J., and S.E.S.; resources, D.R., T.N., S.J., and S.E.S.; data curation, D.R. and S.E.S.; writing-original draft preparation, D.R. and S.E.S.; writing-review and editing, D.R., T.N., S.J., and S.E.S.; visualization, D.R., T.N., S.J., and S.E.S. All authors have read and agreed to the published version of the manuscript.

Funding: This research received no external funding.

Conflicts of Interest: The authors declare no conflict of interest.

\section{References}

1. Araghi, M.; Soerjomataram, I.; Jenkins, M.A.; Brierley, J.; Morris, E.; Bray, F.; Arnold, M. Global trends in colorectal cancer mortality: Projections to the year 2035. Int. J. Cancer 2019, 144, 2992-3000. [CrossRef]

2. Keum, N.; Giovannucci, E. Global burden of colorectal cancer: Emerging trends, risk factors and prevention strategies. Nat. Rev. Gastroenterol. Hepatol. 2019, 16, 713-732. [CrossRef] [PubMed]

3. Rawla, P.; Sunkara, T.; Barsouk, A. Epidemiology of colorectal cancer: Incidence, mortality, survival, and risk factors. Gastroenterol. Rev. 2019, 14, 89-103. [CrossRef]

4. Imaizumi, J.; Shida, D.; Narita, Y.; Miyakita, Y.; Tanabe, T.; Takashima, A.; Boku, N.; Igaki, H.; Itami, J.; Kanemitsu, Y. Prognostic factors of brain metastases from colorectal cancer. BMC Cancer 2019, 19, 755-757. [CrossRef] [PubMed]

5. Schouten, L.J.; Rutten, J.; Huveneers, H.A.M.; Twijnstra, A. Incidence of brain metastases in a cohort of patients with carcinoma of the breast, colon, kidney, and lung and melanoma. Cancer 2002, 94, 2698-2705. [CrossRef]

6. Barnholtz-Sloan, J.S.; Sloan, A.E.; Davis, F.G.; Vigneau, F.D.; Lai, P.; Sawaya, R.E. Incidence Proportions of Brain Metastases in Patients Diagnosed (1973 to 2001) in the Metropolitan Detroit Cancer Surveillance System. J. Clin. Oncol. 2004, 22, 2865-2872. [CrossRef]

7. Tsao, M.N.; Rades, D.; Wirth, A.; Lo, S.S.; Danielson, B.L.; Gaspar, L.E.; Sperduto, P.W.; Vogelbaum, M.A.; Radawski, J.D.; Wang, J.Z.; et al. Radiotherapeutic and surgical management for newly diagnosed brain metastasis(es): An American Society for Radiation Oncology evidence-based guideline. Pr. Radiat. Oncol. 2012, 2, 210-225. [CrossRef]

8. Rades, D.; Panzner, A.; Dziggel, L.; Haatanen, T.; Lohynska, R.; Schild, S.E. Dose-escalation of whole-brain radiotherapy for brain metastasis in patients with a favorable survival prognosis. Cancer 2011, 118, 3852-3859. [CrossRef]

9. Gondi, V.; Pugh, S.L.; Tome, W.A.; Caine, C.; Corn, B.; Kanner, A.; Rowley, H.; Kundapur, V.; DeNittis, A.; Greenspoon, J.N.; et al. Preservation of Memory With Conformal Avoidance of the Hippocampal Neural Stem-Cell Compartment During Whole-Brain Radiotherapy for Brain Metastases (RTOG 0933): A Phase II Multi-Institutional Trial. J. Clin. Oncol. 2014, 32, 3810-3816. [CrossRef]

10. Brown, P.D.; Pugh, S.; Laack, N.N.; Wefel, J.S.; Khuntia, D.; Meyers, C.; Choucair, A.; Fox, S.; Suh, J.H.; Roberge, D.; et al. Memantine for the prevention of cognitive dysfunction in patients receiving whole-brain radiotherapy: A randomized, double-blind, placebo-controlled trial. Neuro Oncol. 2013, 15, 1429-1437. [CrossRef] 
11. Brown, P.D.; Gondi, V.; Pugh, S.; Tome, W.A.; Wefel, J.S.; Armstrong, T.S.; Bovi, J.A.; Robinson, C.; Konski, A.; Khuntia, D.; et al. Hippocampal Avoidance During Whole-Brain Radiotherapy Plus Memantine for Patients With Brain Metastases: Phase III Trial NRG Oncology CC001. J. Clin. Oncol. 2020, 14, JCO1902767. [CrossRef]

12. Sperduto, P.W.; Chao, S.T.; Sneed, P.K.; Luo, X.; Suh, J.; Roberge, D.; Bhatt, A.; Jensen, A.W.; Brown, P.D.; Shih, H.A.; et al. Diagnosis-Specific Prognostic Factors, Indexes, and Treatment Outcomes for Patients With Newly Diagnosed Brain Metastases: A Multi-Institutional Analysis of 4259 Patients. Int. J. Radiat. Oncol. 2010, 77, 655-661. [CrossRef]

13. Sperduto, P.W.; Kased, N.; Roberge, D.; Xu, Z.; Shanley, R.; Luo, X.; Sneed, P.K.; Chao, S.T.; Weil, R.J.; Suh, J.; et al. Summary Report on the Graded Prognostic Assessment: An Accurate and Facile Diagnosis-Specific Tool to Estimate Survival for Patients With Brain Metastases. J. Clin. Oncol. 2012, 30, 419-425. [CrossRef]

14. Dziggel, L.; Segedin, B.; Podvrsnik, N.; Oblak, I.; Schild, S.; Rades, D. A survival score for patients with brain metastases from less radiosensitive tumors treated with whole-brain radiotherapy alone. Strahlenther. und Onkol. 2013, 190, 54-58. [CrossRef]

15. Rades, D.; Hansen, H.C.; Janssen, S.; Schild, S.E. Diagnosis-specific WBRT-30-CRC Score for Estimating Survival of Patients Irradiated for Brain Metastases from Colorectal Cancer. Anticancer Res. 2019, 39, 2569-2574. [CrossRef]

16. Evers, J.N.; Schild, S.E.; Segedin, B.; Nagy, V.; Khoa, M.T.; Trang, N.T.; Rades, D. A new score predicting survival prognosis after whole-brain radiotherapy alone for brain metastases in elderly patients. Anticancer Res. 2014, 34, 2455-2458.

17. Rades, D.; Kieckebusch, S.; Lohynska, R.; Veninga, T.; Stalpers, L.J.; Dunst, J.; Schild, S.E. Reduction of Overall Treatment Time in Patients Irradiated for More Than Three Brain Metastases. Int. J. Radiat. Oncol. 2007, 69, 1509-1513. [CrossRef]

18. Mulvenna, P.; Nankivell, M.; Barton, R.; Faivre-Finn, C.; Wilson, P.; McColl, E.; Moore, B.; Brisbane, I.; Ardron, D.; Holt, T.; et al. Dexamethasone and supportive care with or without whole brain radiotherapy in treating patients with non-small cell lung cancer with brain metastases unsuitable for resection or stereotactic radiotherapy (QUARTZ): Results from a phase 3, non-inferiority, randomised trial. Lancet 2016, 388, 2004-2014.

19. Rades, D.; Sehmisch, L.; Bajrovic, A.; Janssen, S.; Schild, S.E. Comparison of $20 \times 2$ Gy and $12 \times 3$ Gy for Whole-brain Irradiation of Multiple Brain Metastases from Malignant Melanoma. In Vivo 2016, 30, 917-920. [CrossRef]

20. Available online: http://www.who.int/healthinfo/survey/ageingdefnolder/en (accessed on 1 March 2020).

21. Orimo, H.; Ito, H.; Suzuki, T.; Araki, A.; Hosoi, T.; Sawabe, M. Reviewing the definition of "elderly". Geriatr. Gerontol. Int. 2006, 6, 149-158. [CrossRef]

22. Charlson, M.E.; Pompei, P.; Ales, K.L.; MacKenzie, C. A new method of classifying prognostic comorbidity in longitudinal studies: Development and validation. J. Chronic Dis. 1987, 40, 373-383. [CrossRef]

23. Charlson, M.; Szatrowski, T.P.; Peterson, J.; Gold, J. Validation of a combined comorbidity index. J. Clin. Epidemiol. 1994, 47, 1245-1251. [CrossRef]

(C) 2020 by the authors. Licensee MDPI, Basel, Switzerland. This article is an open access article distributed under the terms and conditions of the Creative Commons Attribution (CC BY) license (http://creativecommons.org/licenses/by/4.0/). 